\title{
A Domain-Oriented Analysis of the Impact of Machine Learning-The Case of Retailing
}

\author{
Felix Weber * (D) and Reinhard Schütte \\ Institute for Computer Science and Business Information Systems, University of Duisburg-Essen, \\ 45141 Essen, Germany; reinhard.schuette@icb.uni-due.de \\ * Correspondence: felix.weber@icb.uni-due.de
}

Received: 30 November 2018; Accepted: 22 January 2019; Published: 24 January 2019

check for updates

\begin{abstract}
Information technologies in general and artifical intelligence (AI) in particular try to shift operational task away from a human actor. Machine learning (ML) is a discipline within AI that deals with learning improvement based on data. Subsequently, retailing and wholesaling, which are known for their high proportion of human work and at the same time low profit margins, can be regarded as a natural fit for the application of AI and ML tools. This article examines the current prevalence of the use of machine learning in the industry. The paper uses two disparate approaches to identify the scientific and practical state-of-the-art within the domain: a literature review on the major scientific databases and an empirical study of the 10 largest international retail companies and their adoption of ML technologies in the domain are combined with each other. This text does not present a prototype using machine learning techniques. Instead of a consideration and comparison of the particular algorythms and approaches, the underling problems and operational tasks that are elementary for the specific domain are identified. Based on a comprehensive literature review the main problem types that ML can serve, and the associated ML techniques, are evaluated. An empirical study of the 10 largest retail companies and their ML adoption shows that the practical market adoption is highly variable. The pioneers have extensively integrated applications into everyday business, while others only show a small set of early prototypes. However, some others show neither active use nor efforts to apply such a technology. Following this, a structured approach is taken to analyze the value-adding core processes of retail companies. The current scientific and practical application scenarios and possibilities are illustrated in detail. In summary, there are numerous possible applications in all areas. In particular, in areas where future forecasts and predictions are needed (like marketing or replenishment), the use of ML today is both scientifically and practically highly developed.
\end{abstract}

Keywords: artificial intelligence; machine learning; deep learning; retail; retailing; wholesaling

\section{Introduction}

\subsection{Retailing}

Trade is responsible for balancing the spatial, temporal, qualitative and quantitative distances between production and consumption in every economy based on the division of labor. Trade includes the activities of purchasing goods from different manufacturers or suppliers, transporting, storing and combining the goods to form an assortment, and selling them to commercial (wholesale) or non-commercial (retail) customers without significant modification or processing of the goods. The various types of retail can generally be differentiated between brick and mortar retailing (selling from a fixed location such as a department store, shop or kiosk), distance selling (and mailing) or online retail. In order to structure the analysis of the purpose and potential relevance for the wholesale and retail industries, this article focuses on a reference model to structure a retailer's main 
processes. This overreaching structure will help to group and report the findings structurally within a domain-relevant model. The framework proposed as a reference model to describe a retail task is called the shell model of retail information systems [1]. It contains the master data as a core, the technically engineered, value-adding core and the administrative and decision-making tasks of the retail company from the inside (see Figure 1).

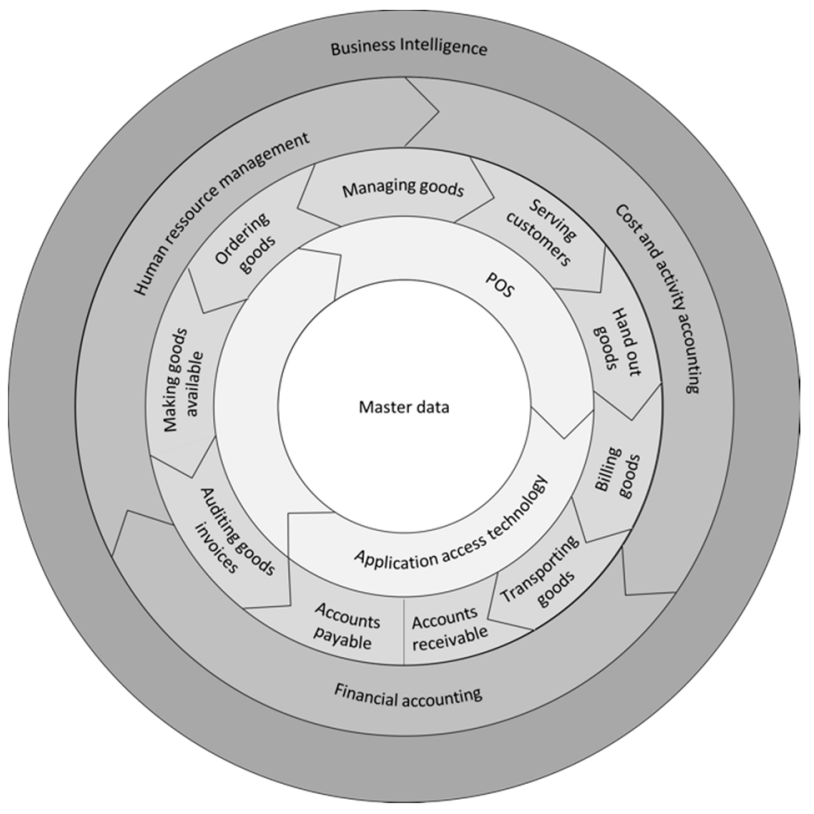

Figure 1. Retail Information system architecture shell model [1].

Since machine-oriented, administrative and decision-making tasks are generic and not primarily different among retail companies, the following article focuses on the core value-added tasks. The reference model summarizes the main value-added retailing tasks according to the shell model as managing goods, ordering goods, serving customers, distributing goods, transporting goods, distributing goods and financial accounting (combining billing goods, accounts payable/receivable and auditing). In accordance with the original architecture [2], the task areas can be recapped as the following components:

First, the management of goods is located in the scientific field of trade marketing, which is defined as analytical processes, target formulation, strategy selection and the composition and control of the marketing mix in a trading company [3,4]. The four areas of the marketing mix are central to the decisions to be taken within the scope of trade marketing. The basic concept of the 4Ps, introduced by McCarthy [5], structures the marketing into four separate components: product, price, location and promotion.

The ordering of goods includes all activities relating to the replenishment of the shops, the filling of the shelves and the reaction to customer requirements. This includes the processes between central warehouses and stores, between suppliers and warehouses, and between suppliers and stores (if directly supplied) depending on the type of trading company. Serving customers includes tasks that are intuitively attributed to trade, such as sales advice and the actual core activities at the cash desks in the store. The operational tasks include the initiation, execution and downstream processes of a transaction (customer service and complaint management).

The transport of goods and logistics includes all tasks related to the storage of goods. This includes any functions related to the creation or management of the warehouse structure for the transfer and management of the warehouse in general-like the management of storage locations and optimization of shelf space. It also covers the operational tasks between central warehouses in the individual stores, from the manufacturer to the direct goods stores, and the coordination of these activities. 
The delivery of goods includes tasks involving the fulfillment of the order according to the agreed quantity, quality and time.

Making goods available and the receipt of goods is the functional field of the planning, acceptance, control, return and physical storage of goods and the parallel execution of these processes.

Financial accounting activities cover all operational activities, such as invoice entry, invoice verification, deviation control, post-processing invoices and subsequent remuneration settlement.

\subsection{Artificial Intelligence (AI) and Machine Learning (ML)}

All efforts within the domain of information technologies, independently of an academically motivated and enforced separation of the research fields, have followed the assumption and goal of the transfer of task to be overtaken by machines in the last decades. Artificial intelligence (AI) was born out of the considerations regarding the extent to which the machine can partially or completely replace humans in the performance of tasks. Following McCarthy et al. [6], artificial intelligence tries to figure out how to get machines to use language, to form abstractions and concepts, to solve types of problems that are currently reserved for humans, and to improve themselves. In addition, it is pointed out here that the ideas of [6-8] are pursued in order to evaluate the use of in retail: AI is the science that enables machines problem types and tasks that cannot yet be performed by computers and in which people are currently better [9]. In this paper it will neither be claimed nor necessary to fully discuss the concept of AI or to deal with philosophical thoughts about intelligence itself [7]. Machine learning (ML), as a subdiscipline of the field of AI, uses techniques for learning from examples, test data, or large data sets to make predictions afterwards. This means that the examples are not simply emulated, but patterns and laws from the data are recognized. After this short introduction to AI and ML, the next step is to evaluate the areas of application and the possible impact especially of ML on the retail sector. Here, we mainly concentrate on the underling business task that are subject to the transfor towards the machine. The retail sector is characterized by an oligopolistic market with strong intra-competition between existing retailers and rising inter-competition between traditional and new "pure" digital players in many countries around the world [1]. With Amazon Fresh about to enter the grocery market, this competition is intensifying. The increased competition, a fading scope for differentiation between operating types [10], increased costs, the overall increased in price knowledge on the customer's side [11] and strong influence of the company's price image on the customer 's choice for a retailer has forced retail companies to find a way to stay competitive.

Due to the nature of stationary trade (bricks-and-mortar stores) in particular, the work areas can be described as focused on manual human activities. This is reflected above all in the high personnel costs of between 12 percent (food) and 40 percent (bakery) of total sales [12]. However, this is not only true for operational activities in direct or indirect customer contexts, but the use of technologies and analyses in the retail trade is traditionally low. Here the core point of the potential impact of the application of ML can be considered.

Also, the operating margins are very low with an average of $0.1 \%$ and a maximum of $3 \%$ [13]. Both aspects together, the relatively high personnel costs on the one hand and the low operating margins on the other, make the retail sector an ideal industry for the application of machine learning. Overall, there is an enormous potential for the transfer of human activities, mainly automated decision and reasoning, to machines.

\section{Research Methodology}

We conducted a search on the major databases EBSCOhost, Google Scholar, JSTOR, Science Direct, SpringerLink, and Wiley Online Library over a period of 10 years (2008-2018) to identify relevant scientific journal articles. To narrow the search down to the application of ML in retailing we used combinations of suitable related problem types (see Section 3): "machine learning", "deep learning", "retail", "wholesaling", "classification", "prediction", "clustering", "optimization", anomaly detection", 
"ranking", "recommendation" and then the value-adding core processes (see Section 4): "making goods available", "ordering goods", "managing goods", "serving customers", "handing out goods", "billing goods", "transporting goods" and "financial accounting" (and related synonyms). With the initial search, a total of 55 matching articles from a total 3505 of were retrieved from the different journals. Following this, every article was carefully reviewed before it was included in the literature review. Because of their focus on manufacturing, logistics or related domains a vast number of publications could not be included. To identify relevant practical applications, we conducted a search on the major English-speaking websites and newspapers with focus on the domain of retailing.

We also included all of the major retail associations: Retail Week, the National Retail Federation, the British Retail Consortium, Retail Focus Magazine and The Grocer. In total we identified 7201 relevant articles. To give an overview about the market adoption within the retail sector, we analyzed the publicly announced ML initiatives and the applications already in use by the largest retail companies (see part 3).

\section{Application of ML Techniques for Different Problem Types in Retailing}

To investigate the pioneers in the application of machine learning technologies, we investigated the 10 largest retailers ranked by their turnover in 2016 [14]. All publicly available current and past ML initiatives are considered and categorized. The categorization follows the major problem types that can be solved using ML techniques [15-17]: classification, estimation, clustering, optimization, anomaly detection, ranking and recommendation (see Figure 2).

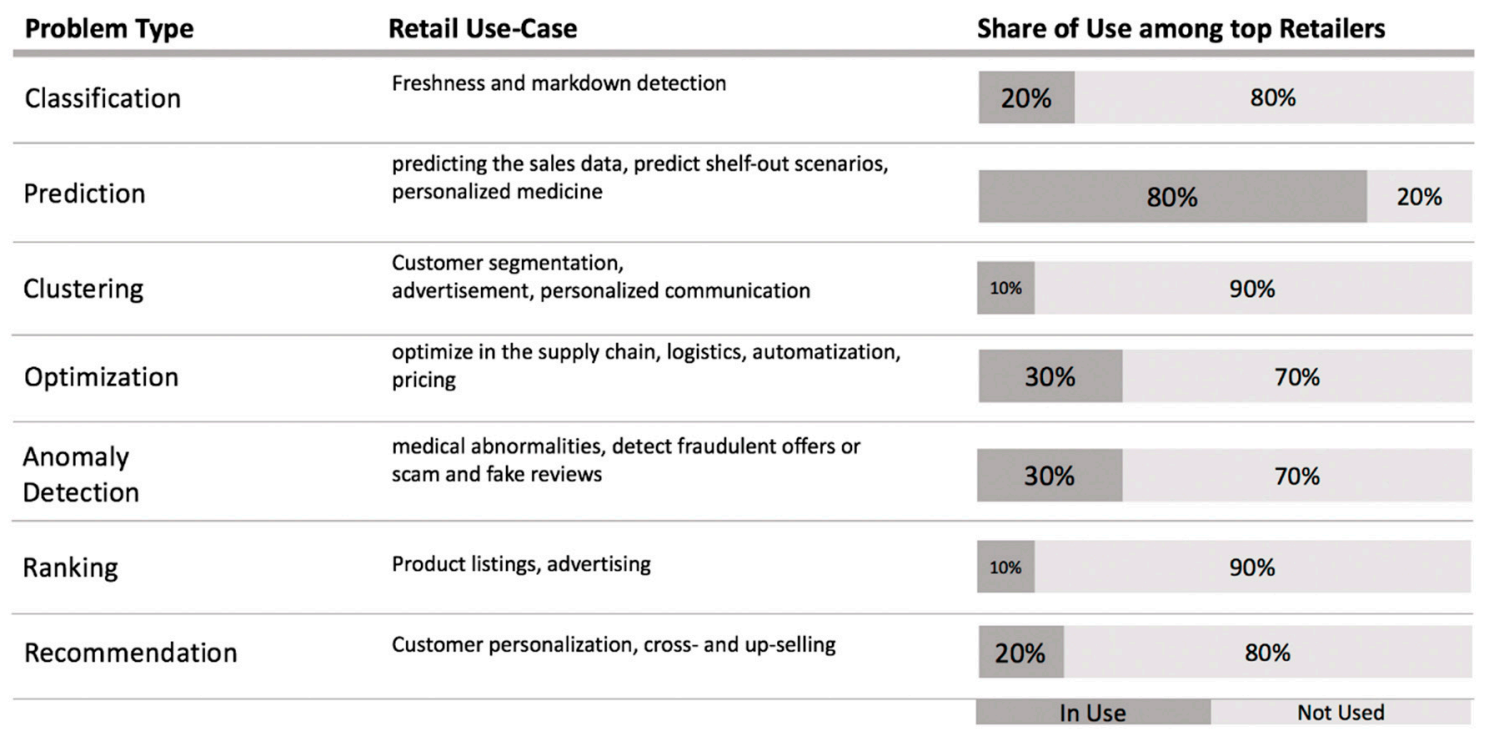

Figure 2. Overview of different problem types, the machine learning (ML) techniques to solve them, mapping use-cases and the diffusion within the largest retail companies.

\subsection{Classification}

Classification is the process by which different objects are regarded as equivalent. In classification, no straight line or curve is predicted that lies through a point cloud, but we want to distinguish point clouds from each other as classes in order to be able to assign points to their correct classes (classification). Walmart, the global US retail group and one of the world's biggest companies, uses a ML system called Eden to categorize the freshness of fruit and vegetables and the timing until they go bad. With a mobile application the staff can photograph the fruits and the system categorizes them into different categories enabling them to decide when to take a markdown or dispose them. France's largest food retailer Carrefour leverages ML and augmented reality for image recognition in its app products [18]. 


\subsection{Prediction}

The aim of predictive analytics is to find out what can happen and why. Therefore, it is a forecasting process with which future events are to be determined. The analyses are based on historical and current data from the company and its environment. The German Schwarz Group, known for its discount chain Lidl, uses predictive analytics within a wine recommendation mobile app for its customers. Based on the historic data of all users the likeliness of a sale is combined with a matching wine. Amazon.com is predicting the sales data for each product in real time related to historic sales and market data. One application is the decision to whether sell a product by themselves or let third-party distributors sell it on their platform. Home Depot, the US DIY retailer, is using deep learning (DL) actively to predict shelf-out scenarios within their stores and automate the replenishment in order to avoid these situations [19]. CVS Health Corporation, an American pharmacy and healthcare company, and Aetna announced their merger to offer a vertically integrated stack of services and touch points in healthcare in 2017 [20]. The analytics company Aetna brings an complete analytics platform and massive data pool that is supposed to deliver more personalized medicine and predictive health services [21].

\subsection{Clustering}

Cluster analyses are methods for discovering similarity structures in data sets. The found groups of "similar" objects are called clusters, the process of group assignment is called clustering. The found similarity groups can be graph-theoretical, hierarchical, partitioning or optimizing. The aim of cluster analysis is to identify new groups in the data (as opposed to classification, where data is assigned to existing classes). An example of clustering is the creation of customer segments, based on data about the demographics, preferences and buyer behavior of existing customers. An example of this problem type shows "84.51", the in-house analytics and marketing company of Kroger. With "Kroger Precision Marketing" the company tries "to amplify the retailer's personalized communication programs" [22] by focusing on deep learning [23].

\subsection{Optimization}

The field of optimization deals with finding optimal parameters of a mostly complex system. "Optimal" means that an objective function is minimized or maximized. Optimization problems arise in business mathematics, statistics, operations research and generally in all scientific disciplines and their practial fields of application in which unknown parameters are used. Walmart optimizes its supply chain using the data from the classification application (Eden). The software is already used in 43 distribution centers [24] and changes the delivery target to a store closer to the distribution center if, for example, the bananas turn brown more quickly due to fluctuating temperatures. The Kroger Company, partnering with Ocado, claims to have the world's most sophisticated automated grocery warehouses powered by deep learning algorithms to navigate and pick product in the most efficient way [25]. Amazon.com is using DL-based optimization to set the most profitable sales price, considering a huge set of different data sources, on their store. Home Depot combines the out-of-stock predictions with DL-based replenishment optimization systems [19].

\subsection{Anomaly Detection}

With anomaly detection, a reference profile is learned from a stream of positive events. The deviation from such a profile is evaluated as an anomaly. The US drugstore chain Walgreens has integrated telemedicine services and apps into its platform services [26]. An application with access to the patient's medical data utilizes deep learning to detect heart abnormalities. Due to the large size of its platform Amazon.com uses outliner analysis based on DL to detect fraudulent offers, scam and fake reviews [27]. CVS Health Corporation and Aetna use their analytics platform for fraud detection on insurance payments [21]. 


\subsection{Ranking}

Ranking algorithms are used where the results of a request or query has to be ordered by some given criterion. Amazon.com is ranking the product search results according to a wide range of factors. Internal properties of the products (e.g., sales, reviews) and also external properties of the search queries or the broader context (e.g., query specificity, customer status) in which the query is issued are considered to train and build DL ranking models [28].

\subsection{Recommendation}

Recommendation systems provide a new suggestion of an artefact, mostly products, based on training data. The most obvious use case in retailing is the recommendation of matching products based on the historic sales data. Lidl offers a chatbot application called "Margot" applying a recommender system in combination with predictive analytics to recommend wine choices to their customers in Great Britain [29]. Amazon.com uses a recommendation system based on ML to suggest related and relevant products to their customers [30]. Carrefour set up a cooperation with Sirqul, a startup focusing on IoT and AI, on a single store smart retail pilot centered around discovering the customer journey and making individual purchase recommendations in Taiwan [31].

\subsection{Diffusion of Machine Learning within the Largest Retail Cooperations}

During the literature review, large differences between the retail companies were detected. Some of the investigated companies showed up at nearly all possible problem types and show publicly announced ML initiatives and active applications. The technologically leading retail company is clearly Amazon.com. The ecommerce giant mainly utilizes their subsidiary A9 for research and development in the field of AI. The spin-off focuses on the development of search and advertising technology and the primary focus is on product search, which is used by all Amazon sites and several other retail companies. Other areas include cloud search, visual search, augmented reality, advertising technology and community question answering. A strong focus lies on utilizing DL technologies for these purposes. But also, the institution in the retail industry, Walmart, exhibits a lot of ML applications that are already in productive use in large part. But also, Kroger and CVS show frequent use of ML. In particular, the retail pharmacy CVS shows a vision and appraisal for the opportunities that might be possible with deep learning technologies. Especially the transformation towards an AI and data-based health care company underlines this vision. With Walgreens, The Home Depot and Carrefour, a set of companies can be categorized into a group of challengers (see Figure 3). These companies have one or more DL-based application not in productive but at least prototypical usage. Interestingly, some of the largest retail companies, the German retail giants ALDI and LIDL, show no signs of any ML applications or initiatives at all. 


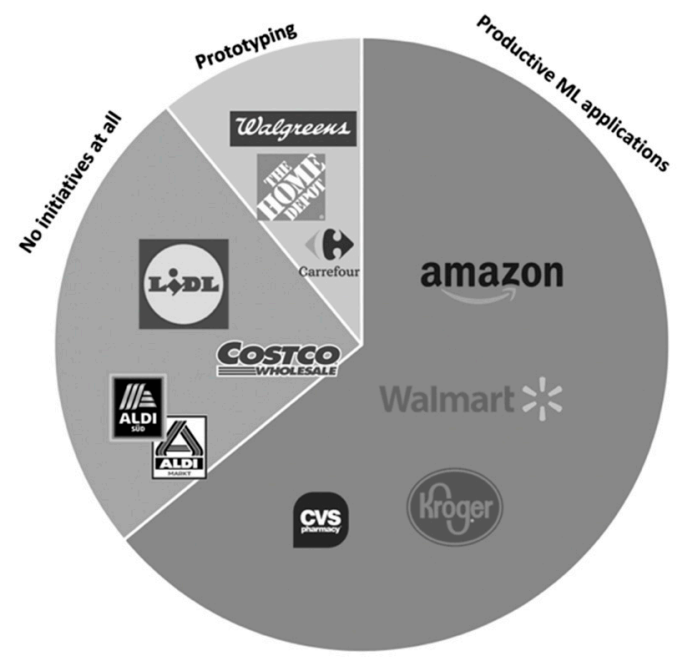

Figure 3. Diffusion of machine learning (ML) within the largest retail companies.

\section{Machine Learning Application Scenarios in the Value-Adding Core Processes}

The results of the literature review show a broad range of different applications currently in use at the worldwide largest retail companies (see Figure 4).

\begin{tabular}{|c|c|c|c|c|c|c|}
\hline \multicolumn{7}{|c|}{ Value-Added Core Tasks of a Retail Company } \\
\hline 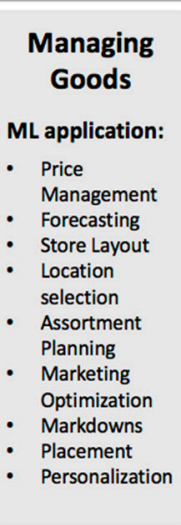 & $\begin{array}{l}\begin{array}{c}\text { Ordering } \\
\text { Goods }\end{array} \\
\text { ML application: } \\
\text { - Replenishment } \\
\text { Optimization } \\
\text { - Optimal } \\
\text { Fulfillment } \\
\text { - Same day } \\
\text { delivery } \\
\text { - Ordering } \\
\text { - Personalization }\end{array}$ & \begin{tabular}{l}
\multicolumn{1}{c}{ Serving } \\
Customers \\
ML application: \\
- Automation of \\
POS \\
- Customer \\
Interaction and \\
Service \\
- Interactive \\
Displays and \\
Digital Signage \\
- Security and \\
Fraud \\
Detection \\
- Virtual \\
Showrooms \\
- Assistants
\end{tabular} & $\begin{array}{l}\text { Transporting } \\
\text { Goods } \\
\text { ML application: } \\
\text { - Intralogistics } \\
\text { - Packaging } \\
\text { - Storage } \\
\text { layout } \\
\text { - Timing } \\
\text { - Disorders } \\
\text { - Supplier } \\
\text { management } \\
\text { - Supply Chain } \\
\text { Optimization } \\
\text { - Risk } \\
\text { Management }\end{array}$ & $\begin{array}{l}\text { Hand out } \\
\text { Goods } \\
\text { ML application: } \\
\text { - Same day } \\
\text { delivery } \\
\text { - Route } \\
\text { optimization } \\
\text { - Fulfillment } \\
\text { strategy }\end{array}$ & $\begin{array}{l}\text { Making } \\
\text { Goods } \\
\text { available } \\
\text { ML application: } \\
\text { - } \quad \text { Automated } \\
\text { shelves } \\
\text { - Vendor } \\
\text { machines } \\
\text { - Incoming } \\
\text { Goods } \\
\text { - Return } \\
\text { Management }\end{array}$ & \begin{tabular}{l}
\multicolumn{1}{c}{ Financial } \\
Accounting \\
ML application: \\
- $\quad$ Automatic \\
reading and \\
interpretation \\
- Autonomous \\
account \\
assignment \\
and processing \\
- Automated \\
reconciliation \\
- Automatization \\
and Decision \\
making
\end{tabular} \\
\hline $\begin{array}{l}\text { ML } \\
\text { techniques } \\
\text { - Prediction } \\
\text { - } \text { Clustering } \\
\text { - Ranking }\end{array}$ & $\begin{array}{l}\text { ML } \\
\text { techniques } \\
\text { - Prediction } \\
\text { - Optimization } \\
\text { - Recommen- } \\
\text { dation }\end{array}$ & $\begin{array}{l}\text { ML } \\
\text { techniques } \\
\text { - Recommen- } \\
\text { dation } \\
\text { - Ranking }\end{array}$ & $\begin{array}{l}\text { ML } \\
\text { techniques } \\
\text { - Prediction } \\
\text { - Optimization }\end{array}$ & $\begin{array}{l}\text { ML } \\
\text { techniques } \\
\text { - Prediction } \\
\text { Optimization }\end{array}$ & $\begin{array}{l}\text { ML } \\
\text { techniques } \\
\text { - Classification } \\
\text { - Anomaly } \\
\text { detection }\end{array}$ & $\begin{array}{l}\text { ML } \\
\text { techniques } \\
\text { - Anomaly } \\
\text { detection } \\
\text { - Classification } \\
\text { - Ranking }\end{array}$ \\
\hline
\end{tabular}

Figure 4. Overview of ML application use-cases and techniques for the value-adding core processes in retailing.

\subsection{Managing Goods}

Machine learning applications for goods management are advanced. In particular, all tasks related to the marketing mix are well suited for ML due to their analytical nature. Both stationary retail and e-commerce are highly dynamic in today's society and prices are also changing rapidly. Complex price management analyzes and decisions can be made using smart and self-learning solutions. As a new development, dynamic pricing [32] is a pricing strategy in which companies adjust prices in real time for products or services based on current market demand. This model calculates prices using ML algorithms, since manual human decisions would not meet the speed and quantity of data required to be considered [33]. 
In stormy weather patterns, for example, hardly any meat is bought for the barbecue; and less sushi is bought in cool compared to hot weather conditions. Short-lived merchandise retailers and manufacturers require precise dealing assumptions for their mark-down administration to auction these items prior to their lifetime [34]. The variables based on quantity planning are more complex than simple meteorological forecasts. Static models have not been sufficiently accurate to date, especially due to the interaction of many factors. They have been at the limit, especially for long-term projections. ML is often used to customize the layout of the store to optimize client experience and sales opportunities [35]. In fact, the assortment of all goods targeted and offered by a retail company, the layout of the assortment and its operational management and control are carried out within the assortment management paradigm. Here, ML selects the right assortments for the various shops and uses adjustments to change customer behavior [36]. ML is also used in ecommerce retail to tailor the customer experience with tailored searches, tailored suggestions or personalized pricing and special offers [37].

\subsection{Ordering Goods}

Replenishment optimization is also an important field for ML applications in retail [38]. Deciding the right time to order the right level to the central warehouse and then to the manufacturers can save significant costs for trading and trading operations. With advancements at the warehouse level [39] it is also possible to limit unsold goods and improve cash flow (as storage costs can not be spent on new products). Another entire area of application is the enhancement of shelf space [40] in the stores and the determination of an optimal fundamental stock [41], so that the shelf always looks full and replenishment is not needed too often. ML algorithms can optimize purchasing and distribution to individual customers [42]. An example of an implementation for protecting the environment (and cost saving) is used at Macys. The retail chain uses ML for replenishment tasks to reduce waste [43]. On the customer side, the enhancement of fulfillment mechanisms [44] within the supply chain can be put into place with AI technologies. In particular, critical and massively complex tasks, such as the collaboration and implementation of the delivery on the same day [45] to end customers, are only made possible by ML. ML also supports the individualisation aspect by empowering an individual order for customers. This can include, for example, an individual's personal order in the local branch [46].

\subsection{Serving Customers}

A main application of ML in this task group is to replace or automate activities at the point of sales (POS). ML-based customer care applications have been developed specifically for digitisation, automation and POS advertising. Here, solutions are based on AI in conjunction with displays, speech assistants and robots. The most far-reaching changes in current processes and tasks concern the use of ML in automated systems for self-regulation [47]. A notable example is Amazon with its Amazon Go-Shop prototype [48]. In line with existing store concepts, robots such as those used in Amazon Robotics, Ocado, Cisco or Softbank [49] for sales support remain unique. At the customer contact and service level, chatbots [29] and voice-supported orders (such as Amazon Echo) [50] are relevant. With regard to interactive displays and digital signage, $\mathrm{AI}$ is used for the targeted advertising of products from a store that refer to age, gender, emotions or objects recognized in real time on a customer's body. For example, the startup "thebirds" and the hardware provider "Sensape" use large displays with a computer system with ML. This makes it possible to recognize the environment to enable interactive and intelligent advertising. Customers can even interact with these displays because they have a motion sensor built in.

\subsection{Transporting Goods}

Autonomous transport systems have been in existence for some time in intralogistics. These trolleys travel on predefined routes from A to B through large warehouses. ML optimises these autonomous systems by actively anticipating environmental situations [51,52] and searching 
for alternative routes, for example in the event of a traffic jam when loading or unloading trucks [53]. Amazon, for example, uses AI to select the ideal packaging size for each shipment [54]. The AI is also used to optimize how many items of each product should be stored in different warehouses, as this varies greatly depending on the warehouse, region, season and major nearby cities [55]. The AI adjusts the optimal stock quantities accordingly. ML is used for delivery and shipping to manage last-minute changes. This includes selecting the best alternative port when the originally scheduled port is blocked, estimating the time of arrival, and measuring the likelihood that a shipper will cancel a commission. IBM and The Weather Company use 100 terabytes of weather data per day to produce location-based weather forecasts and consider possible delays caused by storms, hurricanes and typhoons [56].

\subsection{Handing out Goods}

Given the irregular order patterns, the limited time for processing orders and the short-term delivery schedules (same or next day) offered by e-commerce retailers now expected by customers, logistics providers must be extremely efficient in handling these orders and in managing the entire process of fulfillment [57]. During the formulation of a logistics strategy, ML systems can interactively monitor and optimize all logistics processes and even product characteristics (size, shape and weight) and order demand factors [58]. Here, ML calculates the likelihood that the trucks registered in the system will be on a certain route, their free capacity and the tour cost. Everything is possible in real time and without human interaction. At the same time, ML-powered systems constantly analyze hundreds of thousands of loads, take into account current events and independently learn how prices and timetables are formed. DL technology makes the processes of fulfillment more transparent, reliable and environmentally sound. For example, the Deutsche Post DHL Group has developed a test fleet of autonomous and purely electric vehicles controlled by an ML backend system that takes into account all relevant factors (date of delivery, customer history, price offer, weather conditions, traffic and location specifications) in order to optimally plan the route between warehouses for the same day of delivery and logistics.

\subsection{Making Goods Available}

Supermarket shelves can be automatically filled with integrated shuttles using AI and ML. These shuttles silently transport the goods into a supply chain which is directly integrated in the sales shelf. They are loaded in the supermarket via a replenishment area. It is outside the sales room and cannot be seen by the customer. The shelf and replenishment area is connected directly under the ceiling of the sales room by a connecting network. A shuttle can also deliver several shelves simultaneously. The number of shuttles used depends on the size and the number of shelves in the supermarket. The shelf system is also linked to the supermarket's merchandise management system and the whole shelf is known. The system can, therefore, determine the optimal volume of replenishment and the optimal replenishment time for each item using ML techniques. The start-up company "Tally" has developed a DL robot for retail trade, which completely automatically controls the shelves. The machine searches for empty spaces or incorrectly stored products automatically and travels completely automatically through the shops [59]. If not already dealt with by ML [60], e-commerce retailing must manage many small returns: products that are not returned properly and often do not have an article number in their original packaging. They are therefore manually posted to the system. However, this is only possible if it is possible to determine which article is involved without any doubt. Changing collections seasonally and strong similarities between different fashion pieces make it difficult to identify the right product. A catalog search takes a long time and often involves errors. The catalog images available in the online store can be compared to returns with the help of automatic image recognition. This lets you determine the item number and return the piece of fashion to the system. However, it has been shown in practice that simple image matching is not enough; reflections of glossy materials (jewelry), different perspectives and lighting conditions lead to 
image recognition errors. This is where the potential of the $\mathrm{ML}$, artificial neural networks in concrete terms, comes into play.

\subsection{Financial Accounting}

Systems support is well advanced in the field of financial accounting due to its naturally virtual characteristics. Today, however, large amounts of incoming financial information (bills) are not yet digitized. The first area of application is, therefore, automatic reading and interpreting of documents. Invoices and documents contain a great deal of information, such as invoice items and payment terms. A software system learns to recognize and validate relevant data independently on the basis of deep learning and thousands of previous expert inputs [61,62]. Digital processes without paper reduce costs and improve efficiency. In the next step, systems are used to predict the assignment of accounts with a high probability and completely automatic processing of all process steps involved. The reconciliation of account information and receipts and the assignment of bank information via artificial intelligence are possible. The software directly accesses both data sources. Algorithms for self-learning compare document information to transactions in bank accounts of the company. This makes the banking reconciliation process even more reliable compared to human review, and can be carried out daily or at any time. The financial accounting software used with the use of ML no longer helps the accountant digitally, but handles the accounting largely independently. This requires procedures for accurately recognizing invoices and receipts of all types, followed by automatic account assignment, payment clearance, detection of anomalies such as price deviations of individual items and automatic routine calculation and receipts. For systems covering the entire process from handling incoming documents to final clearing, the software must be able not only to recognize what is available, but also to deal with what is not or only approximately recognizable. Therefore, it must be able to control blurredness and vagueness. This can be achieved using ML and general AI methods like fuzzy logic.

\section{Discussion}

In summary, it can be stated that there is a multitude of possible applications of ML in all areas of retail and wholesale. Within the various value-adding core tasks, the number of conceivable (scientific and practical) applications varies greatly.

In particular, in areas where predictions are required in the task areas (such as marketing or replenishment), the use of ML is today both scientifically and practically highly developed, similar to other domains like medicine. So the application area of ML within the domain of retail is less about the replacement of the sales clerk by oneself, but rather the support and automatization of marketing decisions. Here, ML is particularly relevant for decision support and analysis and is also used in practice. Due to the particular circumstances of the retail trade, the number of obstacles to data analysis is particularly high. For instance, the massive assortment and rapid sequence of sales multiplied by thousands of stores leads to a data quantity that cannot be analyzed by humans. The lack of need to analyze this data in the past, and the lack of technical feasibility $[63,64]$ in most current architectural systems for information systems are the reasons why the priority for analytical applications and, therefore, $\mathrm{AI}$ and $\mathrm{ML}$, was traditionally low in retail in the past [65].

The complexity resulting from the multiplication of a large number of possible influencing factors, e.g. the composition of the product range, the placement within the store, the competition and its promotions, as well as the advertising activities or market effects, are major challenges. Here, ML proposes a solution to solve these problems without the need of knowing all the relevant influencing factors. In the areas that interact directly with the customer, particularly few deep learning techniques can be seen. This is, of course, due to the stationary nature of retail. With the introduction of Omnichannel commerce, the rise of ML-related applications can certainly be observed. Prominent examples are chat bots interacting directly with the client. Low consumption applies to all processes associated with the physical movement of products. Here the use of robots is possible, but due to the aforementioned cost structure in retail this is not economical for most companies or at least not 
meaningful enough to invest. Only "exotic" realizations like Amazon 's checkout-free grocery store, "Amazon Go", are notable exceptions.

The enormous opportunities to both reduce the traditionally high cost of human resources in retail and optimize low-margin business show the great, but not yet widespread possibilities of applying machine learning techniques and methods in retail. Looking at the market acceptance in the largest retail companies, the same pattern can be observed. There are some pioneers (Amazon, Walmart) who have integrated extensive applications into their daily business and use ML as a key innovation and differentiation opportunity for themselves. Some challengers like Walgreens or The Home Depot seem to have followed this idea and are currently investing heavily in new initiatives but have few applications in production. However, many other retail companies are not actively using ML or making efforts to invest in ML applications in the future. In the long term and from a scientific point of view, it will be interesting to examine whether the financial and competitive success of the companies investigated is in any way related to early or late investments in AI and ML technologies.

Author Contributions: Conceptualization, F.W. and Reinhard Schütte; Project administration, F.W.; Writingoriginal draft, F.W. and Reinhard Schütte; Writing_-review and editing, Reinhard Schütte.

Conflicts of Interest: The authors declare no conflict of interest.

\section{References}

1. Schütte, R. Information Systems for Retail Companies. In Proceedings of the 29th International Conference on Advanced Information Systems Engineering, CAiSE 2017, Essen, Germany, 12-16 June 2017; Dubois, E., Pohl, K., Eds.; Springer: Berlin, Germany, 2017; pp. 13-25.

2. Becker, J.; Schütte, R. Handelsinformationssysteme Domänenorientierte Einführung in die Wirtschaftsinformatik, 2nd ed.; Redline-Wirtschaft: Frankfurt/M., Germany, 2004.

3. Borden, N.H. The concept of the marketing mix. J. Advert. Res. 1964, 4, 2-7.

4. Haller, S. Handelsmarketing; 3. Auflage ed. Modernes Marketing für Studium und Praxis, ed.; Weis, H.-C., Ed.; Fridrich Kiehl Verlag: Ludwigshafen, Germany, 2008.

5. McCarthy, E. Basic Marketing: A Managerial Approach; Irwin: Georgtown, IN, USA, 1960.

6. McCarthy, J.; Minsky, M.L.; Rochester, N.; Shannon, C.E. A proposal for the dartmouth summer research project on artificial intelligence. AI Mag. 1955, 27, 12.

7. Computing Machinery and Intelligence. Available online: https://books.google.com.hk/books?

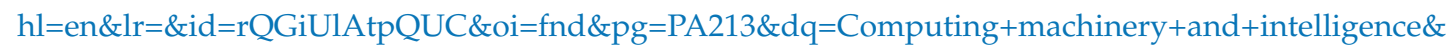
ots=VXvI7lAhTg\&sig=aacArMhq_3blRum6IV3NX6NEEnE\&redir_esc=y\#v=onepage\&q=Computing\% 20machinery\%20and\%20intelligence \&f=false (accessed on 22 January 2019).

8. Russell, S.J.; Norvig, P. Artificial Intelligence: A Modern Approach; Pearson Education Limited: Kuala Lumpur, Malaysia, 2016.

9. Goldberg, D.E.; Holland, J.H. Genetic algorithms and machine learning. Mach. Learn. 1988, 3, 95-99. [CrossRef]

10. Meffert, H.; Burmann, C.; Kirchgeorg, M. Marketing: Grundlagen Marktorientierter Unternehmensführung Konzepte_Instrumente_Praxisbeispiele, 12th ed.; Springer Fachmedien Wiesbaden: Wiesbaden, Germany, 2015; pp. 357-768.

11. Daurer, S.; Molitor, D.; Spann, M. Digitalisierung und Konvergenz von Online-und Offline-Welt. Zeitschrift für Betriebswirtschaft 2012, 82, 3-23. [CrossRef]

12. Glaeser, H.R. Qualitätsbausteine für die Beschäftigung im Einzelhandel. In Landschaftsverband Westfalen-Lippe Messe der Integrationsunternehmen; LWL: Münster, Germany, 2014.

13. Lorentschitsch, B. Der Lebensmittelhandel im Spannungsfeld zwischen gesellschaftlicher Verantwortung und Geiz ist geil. In CSR und Lebensmittelwirtschaft; Willers, C., Ed.; Springer: Berlin, Germany, 2016; pp. 331-344.

14. EHI Retail Institute. Nettoumsatz der Weltweit Größten Einzelhändler. 2016. Available online: https:/ / www.handelsdaten.de/nettoumsatz-der-weltweit-groessten-einzelhaendler-2016 (accessed on 11 November 2017). 
15. Michalski, R.S.; Carbonell, J.G.; Mitchell, T.M. Machine Learning: An Artificial Intelligence Approach; Springer Science \& Business Media: Berlin, Germany, 2013.

16. Jordan, M.I.; Mitchell, T.M. Machine learning: Trends, perspectives, and prospects. Science 2015, 349, $255-260$. [CrossRef] [PubMed]

17. Chui, M.; Francisco, S. Artificial Intelligence the Next Digital Frontier? McKinsey and Company Global Institute: New York, NY, USA, 2017; Volume 47.

18. Retail Week Live: How Are Retailers Leading the Way with AI? Available online: https://www.retailweek.com/retail-week-live/retail-week-live-early-adopters-of-ai-will-benefit/7028186.article?authent=1 (accessed on 2 Jaunary 2018).

19. Home Depot to Add 1,000 Tech Jobs. Available online: https://www.retaildive.com/news/home-depot-toadd-1000-tech-jobs/521673/ (accessed on 22 July 2018).

20. CVS Health and Aetna Bet $\$ 69$ Billion Merger on Analytics, Data, Digital Transformation. Available online: https: / / www.zdnet.com/article/cvs-health-and-aetna-bet-69-billion-merger-on-analytics-data-digitaltransformation/ (accessed on 8 July 2018).

21. Using Advanced Analytics to Smooth Member Transitions. Available online: https://payorsolutions. cvshealth.com/insights/using-advanced-analytics-to-smooth-member-transitions (accessed on 11 May 2018).

22. Kroger Using Data, Technology to 'Restock' for the Future. Available online: https:/ / consumergoods.com/ kroger-using-data-technology-restock-future (accessed on 8 Jaunary 2018).

23. $84.51^{\circ}$ Builds a Machine Learning Machine for Kroger. Available online: https://www.forbes.com/ sites/tomdavenport/2018/04/02/84-51-builds-a-machine-learning-machine-for-kroger/ (accessed on 11 July 2018).

24. Eden: The Tech That's Bringing Fresher Groceries to You. Available online: https://blog.walmart.com/ innovation/20180301/eden-the-tech-thats-bringing-fresher-groceries-to-you (accessed on 12 March 2018).

25. Kroger Finally Realizes It Needs Tech to Survive. Available online: https://techhq.com/2018/05/krogerfinally-realizes-it-needs-tech-to-survive/ (accessed on 20 August 2018).

26. See a Doctor Virtually with MDLIVE. Available online: https://www.walgreens.com/topic/pharmacy/ virtualdoctor.jsp (accessed on 22 August 2018).

27. Amazon Scams On The Rise As Fraudulent Sellers Run Amok And Profit Big. Available online: https: / /www.forbes.com/sites/wadeshepard/2017/01/02/amazon-scams-on-the-rise-in-2017-asfraudulent-sellers-run-amok-and-profit-big/\#5261789f3ea6 (accessed on 1 November 2018).

28. Sorokina, D.; Cantú-Paz, E. Amazon Search: The Joy of Ranking Products. In Proceedings of the 39th International ACM SIGIR conference on Research and Development in Information Retrieval, Tuscany, Italy, 17-21 July 2016.

29. Lidl Launches Online Chatbot That Recommends Wine Based on Your Budget and Food Choices. Available online: https://www.telegraph.co.uk/business/2018/01/31/lidl-launches-online-chatbotrecommends-wine-based-budget-food/ (accessed on 1 Feburary 2018).

30. Linden, G.; Smith, B.; York, J. Amazon.com recommendations: Item-to-item collaborative filtering. IEEE Internet Comput. 2003, 7, 76-80.

31. Carrefour and Sirqul Launch Smart Retail Store in Taiwan. Available online: https://corp.sirqul.com/ carrefour-sirqul-launch-smart-retail-store-taiwan/ (accessed on 11 June 2018).

32. Kephart, J.O.; Hanson, J.E.; Greenwald, A.R. Dynamic pricing by software agents. Comput. Netw. 2000, 32, 731-752. [CrossRef]

33. Jaekel, M. Die Macht der Digitalen Plattformen: Wegweiser im Zeitalter Einer Expandierenden Digitalsphäre und künstlicher Intelligenz; Springer: Wiesbaden, Germany, 2017.

34. Kuo, R.J.; Wu, P.; Wang, C. An intelligent sales forecasting system through integration of artificial neural networks and fuzzy neural networks with fuzzy weight elimination. Neural Netw. 2002, 15, 909-925. [CrossRef]

35. New Virtual Store Remodeling Solution Enables Customer-Driven Store Design and Testing in a Virtual Reality Environment. Available online: https:/ / www.symphonyretailai.com/new-virtual-store-remodelingenables-customer-driven-store-design-testing/ (accessed on 11 August 2018).

36. Leo Kumar, S.P. State of The Art-Intense Review on Artificial Intelligence Systems Application in Process Planning and Manufacturing. Eng. Appl. Artif. Intell. 2017, 65, 294-329. [CrossRef] 
37. Montgomery, A.L.; Smith, M.D. Prospects for Personalization on the Internet. J. Interactive Mark. 2009, 23, 130-137. [CrossRef]

38. Blue Yonder's Technology Delivers Improved Product Availability for Morrisons With Shelf Gaps Down 30\%. Available online: https://www.blueyonder.ai/sites/default/files/by-en-case-study-morrisons_0.pdf (accessed on 22 July 2018).

39. Šustrová, T. A Suitable Artificial Intelligence Model for Inventory Level Optimization. Trends Econ. Manag. Trendy Ekon. Manag. 2016, 10, 48-55. [CrossRef]

40. Landa-Silva, D.; Marikar, F.; Le, K. Heuristic approach for automated shelf space allocation. In Proceedings of the 2009 ACM Symposium on Applied Computing, Honolulu, HI, USA, 9-12 March 2009.

41. Huh, W.T.; Janakiraman, G.; Muckstadt, J.A.; Rusmevichientong, P. An adaptive algorithm for finding the optimal base-stock policy in lost sales inventory systems with censored demand. Math. Oper. Res. 2009, 34, 397-416. [CrossRef]

42. Get Under Customers' Skin with AI Personalisation. Available online: https://www.thegrocer.co.uk/ channels/online/get-under-customers-skin-with-ai/554223.article (accessed on 20 August 2018).

43. Weinbren, E. M\&S to Use Artificial Intelligence to Reduce Bakery Waste. 2017. Available online: https:/ / m.thegrocer.co.uk/home/topics/waste-not-want-not/ms-to-use-artificial-intelligence-to-reducebakery-waste/560456.article (accessed on 20 August 2018).

44. Ning, A.; Lau, H.C.; Zhao, Y.; Wong, T.T. Fulfillment of Retailer Demand by Using the MDL-Optimal Neural Network Prediction and Decision Policy. IEEE Trans. Ind. Inform. 2009, 5, 495-506. [CrossRef]

45. Kawa, A.; Pieranski, B.; Zdrenka, W. Dynamic Configuration of Same-Day Delivery in E-commerce. In Modern Approaches for Intelligent Information and Database Systems; Sieminski, A., Ed.; Springer: Berlin, Germany, 2018; pp. 305-315.

46. Dennis, L. Future of Retail Round-Up. 2018. Available online: http://www.retail-focus.co.uk/features/ 1339-future-of-retail-round-up (accessed on 20 August 2018).

47. Bertasius, G.; Park, H.S.; Yu, S.X.; Shi, J. First person action-object detection with egonet. arXiv 2016, arXiv:1603.04908.

48. Rüschen, S.; Wiehenbrauk, D. Disruption in Retail-Retail 4.0. In Mobile Payment; Springer: Berlin, Germany, 2017; pp. 49-65.

49. Frangoul, A. How Robots Are Helping to Shape the Future of Retail. 2017. Available online: https: / / www.cnbc.com/2017/11/22/how-robots-are-helping-to-shape-the-future-of-retail.html (accessed on 11 May 2018).

50. Holmqvist, J.; van Vaerenbergh, Y.; Grönroos, C. Language use in services: Recent advances and directions for future research. J. Bus. Res. 2017, 72, 114-118. [CrossRef]

51. Pierdicca, R.; Liciotti, D.; Contigiani, M.; Frontoni, E.; Mancini, A.; Zingaretti, P. Low cost embedded system for increasing retail environment intelligence. In Proceedings of the 2015 IEEE International Conference on Multimedia \& Expo Workshops (ICMEW), Turin, Italy, 29 June-3 July 2015.

52. Tarantilis, C.D.; Kiranoudis, C.T. A flexible adaptive memory-based algorithm for real-life transportation operations: Two case studies from dairy and construction sector. Eur. J. Oper. Res. 2007, 179, 806-822. [CrossRef]

53. Wurman, P.R.; D'Andrea, R.; Mountz, M. Coordinating hundreds of cooperative, autonomous vehicles in warehouses. AI Mag. 2008, 29, 9.

54. Stevens, L.; Phillips, E. Amazon Puzzles Over the Perfect Fit-in Boxes. 2017. Available online: https: / / www.wsj.com/articles/amazon-aims-for-one-box-fits-all-1513765800 (accessed on 20 Jaunary 2018).

55. Xu, X.-F.; Chang, W.-H.; Liu, J. Resource allocation optimization model of collaborative logistics network based on bilevel programming. Sci. Programm. 2017, 2017, 4587098. [CrossRef]

56. Armstrong, L. The Weather Company, an IBM Business, Introduces New Solutions Designed to Help Freight and Logistic Companies Improve Operational Efficiency. 2017. Available online: https:/ /www-03.ibm.com/ press/us/en/pressrelease/52381.wss (accessed on 28 August 2018).

57. Leung, K.H.; Choy, K.L.; Siu, P.K.; Ho, G.T.; Lam, H.Y.; Lee, C.K. A B2C e-commerce intelligent system for re-engineering the e-order fulfilment process. Expert Syst. Appl. 2018, 91, 386-401. [CrossRef]

58. Lam, H.Y.; Choy, K.L.; Ho, G.T.S.; Cheng, S.W.; Lee, C.K.M. A knowledge-based logistics operations planning system for mitigating risk in warehouse order fulfillment. Int. J. Prod. Econ. 2015, 170, 763-779. [CrossRef] 
59. Vanian, J. Why Walmart Is Testing Robots In Stores-And Here's What It Learned. 2018. Available online: http:/ / fortune.com/2018/03/26/walmart-robot-bossa-nova/ (accessed on 1 May 2018).

60. Kumar, D.T.; Soleimani, H.; Kannan, G. Forecasting return products in an integrated forward/reverse supply chain utilizing an ANFIS. Int. J. Appl. Math. Comput. Sci. 2014, 24, 669-682. [CrossRef]

61. Suponenkovs, A.; Sisojevs, A.; Mosāns, G.; Kampars, J.; Pinka, K.; Grabis, J.; Taranovs, R. Application of image recognition and machine learning technologies for payment data processing review and challenges. In Proceedings of the 2017 5th IEEE Workshop on Advances in Information, Electronic and Electrical Engineering (AIEEE), Riga, Latvia, 24-25 November 2017.

62. Arianto, A.D.; Affandi, A.; Nugroho, S.M.S. Opinion detection of public sector financial statements using K-nearest neighbors. In Proceedings of the 2017 4th International Conference on Electrical Engineering, Computer Science and Informatics (EECSI), Yogyakarta, Indonesia, 19-21 September 2017.

63. McAfee, A.; Brynjolfsson, E. Big data: The management revolution. Harvard Bus. Rev. 2012, 90, 60-68.

64. Litzinger, D. Computergestütztes Promotioncontrolling: Konzeption eines Informationssystems für das Controlling von Konsumgüterpromotions; Springer: Berlin, Germany, 2013.

65. Schütte, R.; Vetter, T. Analyse des Digitalisierungspotentials von Handelsunternehmen. In Handel 4.0; Springer: Berlin, Germany, 2017; pp. 75-113.

(c) 2019 by the authors. Licensee MDPI, Basel, Switzerland. This article is an open access article distributed under the terms and conditions of the Creative Commons Attribution (CC BY) license (http://creativecommons.org/licenses/by/4.0/). 